\title{
The Effect of Exogenous Melatonin in the Regulation of the Degradation of Residual Fungicide in Tomato
}

\author{
YU GAOBO ${ }^{1,2}$, CHEN RUNAN ${ }^{2}$, WEIJINPENG ${ }^{2}$, CHEN PENG ${ }^{2}$, ZHOU XINGANG ${ }^{1}$, \\ WU FENGZHI ${ }^{*}$ \\ ${ }^{1}$ Northeast Agricultural University, College of Horticulture and Landscape Architecture, Department of Agricultural Facility \\ Science and Engineering, Heilongjiang, Haerbin 163000, China \\ ${ }^{2}$ Heilongjiang Bayi Agricultural University, College of Horticulture and Landscape Architecture, Department of \\ Agricultural Facility Science and Engineering, Heilongjiang, Daqing 163319, China
}

\begin{abstract}
Fungicides are widely used to control pathogen in modern agriculture. In particular, in the process of vegetable production, the use of fungicides could control a variety of diseases to increase crop yield. However, it is common that excessive and unsuitable application of pesticide cause serious pesticide residue in vegetables, which leads to problems of food safety and environment pollution. Therefore, it should not be ignored to reduce fungicide residue in vegetable. In order to confirm the effect of exogenous melatonin on degradation of residual fungicide in plant and explore the mechanism of regulation, Chlorothalonil was taken as experiment material in the present study, and exogenous melatonin was applied as pretreatment to investigate the mechanism of the degradation of residual Chlorothalonil in tomato. It is demonstrated that exogenous melatonin pretreatment could promote the degradation and metabolism of $\mathrm{CHT}$ residue in tomato plants by inducing the redox signal, improving the antioxidant system, enhancing antioxidant enzymes and increasing the ratio of GSH/GSSG to scavenge reactive oxygen species. And the activity of GST and GR enzymes were also enhanced to conduct detoxification, which result in a pronounced decrease in the residue of CHT in tomato.
\end{abstract}

Keywords: fungicide degradation, melatonin, redox, detoxification, antioxidant

\section{Introduction}

Pesticides are widely used to control pathogen, pest and weed in modern agriculture, while the crop production may be lost by $80 \%$ without pesticides [1]. In the process of vegetable production, the use of pesticides could also control a variety of diseases and pests, and increase crop yield to a certain extent [2]. However, it is common that excessive and unsuitable application of pesticide cause serious pesticide residue in vegetables, which leads to a decline in the quality of agricultural products and by-products, and also results in pollution to the environment in the world [3]. Problems of food safety and environment pollution could endanger human health directly or indirectly [4] It is mentioned that pesticide residual in vegetable could cause both acute and chronic poisoning, which may cause cancer and other chronic diseases. Hence it should not be ignored that the problem of pesticide residues in vegetables rises a serious threat to food safety and human health. Therefore, how to reduce pesticide residue in vegetable has become an urgent problem.

Pesticide residues on the surface of vegetables and fruits could be removed by washing, soaking and peeling, while the other part of pesticides entering into fruits and vegetables cannot be removed by conventional methods [5]. However, low dose of toxic ingredients also do harm to human health directly or endanger human health indirectly, through the enrichment of the food chain in ecological environment, or even cause human congenital abnormalities and other problems [6]. Therefore, it has become an urgent problem to reduce pesticide residues in vegetables and explore the mechanism of degradation of residual pesticides in plants. Some studies focus on the degradation and mechanism of herbicide residue in plants [7]. In fact, it has been explored that plants have developed its detoxification mechanism to degrade and metabolic exogenous herbicide and relieve the negative impacts of herbicide [8].

\footnotetext{
*email: yugaobo81@163.com
} 
Glutathione plays a critical role in the regulation of herbicides metabolism, due to its function in both detoxification of toxic ingredients and protection of cells against free radicals [9]. However, most studies are concentrated in the degradation metabolism of herbicide residue, whose target is plant, while there are only a limited study focused on the degradation metabolism of pesticides in plants, especially on the degradation of fungicides. As a matter of fact, in the process of vegetable production, number types of germicidal pesticides are used to control plant diseases. Among them, Chlorothalonil $(2,4,5$, 6tetrachloroisophthalonitrile, CHT) is widely used in the prevention of diseases in vegetable and other crop production, due to its efficient inhibition of pathogens growth. However, chemical properties of Chlorothalonil are stable, which is difficult to degrade under natural conditions because of low water solubility. As a result, it is also easy to form pesticide residue in vegetables. Therefore, the safety problem caused by chlorothalonil residue in vegetable cannot be ignored.

It is mentioned that hormone treatment could improve plant resistance to abiotic stresses and regulate the mechanism of exogenous substances. And Brassinosteroids has been demonstrated to be a positive regulation factor that promote the degradation of pesticides residue in vegetables in our previous study [1]. Although a great many studies indicate positive effects of exogenous melatonin on plant resistance to abiotic stresses, until now, little is known about the effect of exogenous melatonin in the regulation of the degradation of residual fungicide in vegetables [10-12]. And the regulation mechanism of exogenous melatonin in residual fungicide degradation in plants is still not clear. In order to confirm the effect of exogenous melatonin on degradation of residual fungicide in plant and explore the mechanism of regulation, Chlorothalonil was taken as experiment material in the present study, and exogenous melatonin was applied as treatment to investigate the mechanism of the degradation of residual Chlorothalonil in tomato.

\section{Materials and methods}

\subsection{Plant materials}

Tomato (Guanghui 101) seeds were grown in a mixture with peat and vermiculite (7:3). The tomato plants were cultured in the growth conditions: the temperature was kept at $25^{\circ} \mathrm{C}$ with $120 \mathrm{~mol} \mathrm{~m} / \mathrm{s}$ light for $14 \mathrm{~h}$ in the daytime, and the temperature was kept at $20^{\circ} \mathrm{C}$ in the dark for $10 \mathrm{~h}$.

\subsection{Chemical treatments and sample harvesting}

Tomato plants with 6 true leaves fully expanded were pretreated with melatonin $(3 \mathrm{mM})$ as treatment (Sigma, USA), while deionized water was utilized as control to explore the effect of melatonin (MT) in the regulation of fungicide degradation. $24 \mathrm{~h}$ after pretreatment, tomato leaves were sprayed with chlorothalonil (CHT) at $11.2 \mathrm{mM}$ with $30 \mathrm{~mL}$ per plant (commercial CHT $75 \%$ active ingredient, Shenzhen Noposion Agrochemicals Co., Ltd.). The plant tissues were sampled at 0, 3, 6, 12, 24, 36, 48, $96 \mathrm{~h}(4 \mathrm{~d})$, and $168 \mathrm{~h}(7 \mathrm{~d})$ after CHT treatment for biochemical analysis. And plant samples were harvested $7 \mathrm{~d}$ after CHT application to analyze the residue of CHT in tomato plants.

\subsection{Measurement of the content of GSH and GSSG}

The content of GSH and GSSG were measured according to the method of Rahman and Kode (Rahman et al., 2007).

\subsection{Assay of GST and GR activity}

$0.3 \mathrm{~g}$ leaf samples were extracted in $2 \mathrm{~mL} 50 \mathrm{mM}$ PBS buffer $(p \mathrm{H} 7.5)$ with $10 \mathrm{mM} \mathrm{KCl}, 1 \mathrm{mM}$ EDTA, 5mM DTT, 0.5mM AEBSF and 1:4 insoluble PVPP to determine the activity of glutathione reductase (GR) and glutathione S-transferase (GST). The homogenates of plant tissue were centrifuged at $14000 \mathrm{rpm}$ for $20 \mathrm{~min}$, and the supernatants were used to analyze the activity of enzyme. The activity of GST was measured at the absorbance of $412 \mathrm{~nm}$ as described by Xia et al [13]. The activity of GR was assayed dependent on the rate of decrease at the absorbance of $340 \mathrm{~nm}$ according to Xia et al. [13]. 


\subsection{Analysis of Antioxidant enzymes activity}

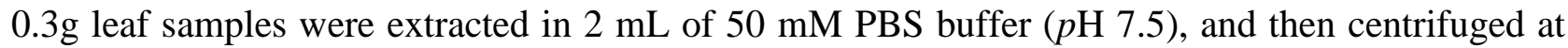
$12000 \mathrm{~g}$ for $20 \mathrm{~min}$, and the supernatants were used to analyze the activity of enzymes. The activity of SOD, POD, CAT, APX, and MDAR were assayed according to the methods of Erkan et al. [14].

\subsection{Investigation of the content of $\mathrm{H}_{2} \mathrm{O}_{2}$ and $\mathrm{O}_{2}$}

The level of $\mathrm{H}_{2} \mathrm{O}_{2}$ and $\mathrm{O}_{2}$ were determined according to the methods of $\mathrm{Zhu}$ et al. [15].

\subsection{Quantification of CHT in plant tissue}

To assay the level of CHT residue in tomato, $10 \mathrm{~g}$ tomato leaves were extracted with $80 \mathrm{~mL}$ petroleum ether including $40 \mathrm{~g} \mathrm{Na}_{2} \mathrm{SO}_{4}$ for $12 \mathrm{~h}$ and then filtered, and the filtrates were collected and dried with rotary evaporators. To analyze the level of CHT, N-hexane was used to dissolve pesticide, and the volume was adjusted to $5 \mathrm{~mL}$, and gas chromatography (GC) with ECD and a capillary column (30m length, $0.32 \mathrm{~mm}$ internal diameter and $0.25 \mu \mathrm{m}$ film thickness) (Agilent, Santa Clara, CA, USA) was applied. Nitrogen $\left(3.3 \mathrm{mLmin}^{-1}\right)$ was employed as carrier gas, and the injector port temperature was set at $250^{\circ} \mathrm{C}$, while the detector temperature was set at $300{ }^{\circ} \mathrm{C}$, and column temperature was raised from 80 to $260^{\circ} \mathrm{C}\left(25^{\circ} \mathrm{C} / \mathrm{min}\right)$, and then maintained for $3.8 \mathrm{~min}$. CHT (Institute for the Control of Agrochemicals, Ministry of Agriculture, Beijing, China) was applied was used as standard. The level of residual CHT in plant tissue was determined according to the standard method [16].

\subsection{Statistical analysis}

Assay was all performed with three replicates. SPSS was used to analyze the statistic. The data were subjected to analysis of variance, and the means were compared using Tukey's test at the 5\% level.

\section{Results and discussions}

\subsection{Effect of melatonin pretreatment on chlorothalonil residue in tomato}

Chlorothalonil is one of the most common fungicides, which could effectively act on common diseases in vegetable production, such as downy mildew and powdery mildew. In order to explore whether melatonin pretreatment do have positive influence in the fungicide residue degradation metabolism in plants, the content of CHT residue in tomato with or without melatonin were determined. Compared with the control, pretreatment with melatonin (MT) significantly decreased the residue of CHT in the tomato plants and the level of CHT residue reduced by $30.27 \%$ (Figure 1). The results revealed that exogenous MT could promote the degradation and metabolism of chlorothalonil effectively in tomato leaves and reduce the residue of chlorothalonil in tomatoes.

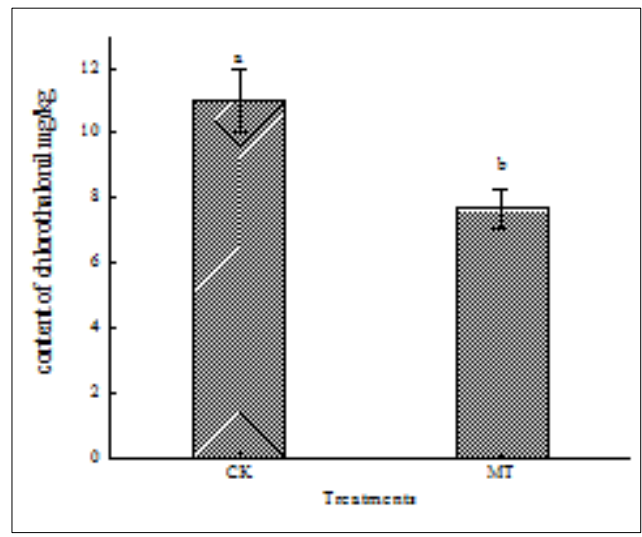

Figure 1. Effect of melatonin pretreatment

on chlorothalonil residue in Tomato

Different letters indicate significant difference between the data $(\mathrm{P}<0.05)$ 


\subsection{Effects of melatonin pretreatment on $\mathrm{ROS}$ production rate and the level of $\mathrm{H}_{2} \mathrm{O}_{2}$ in tomato leaves with CHT application}

As shown in Figure 2, the production of ROS and the level of $\mathrm{H}_{2} \mathrm{O}_{2}$ in tomato leaves were induced with melatonin pretreatment, however, the level of which were significantly lower than control pretreated with water since 12-24 $\mathrm{h}$ after CHT application. Compared to the control, the ROS production rate of tomato leaves pretreated by exogenous MT was significantly increased during 0-3 h after CHT treatment, while the ROS production rate of tomato leaves pretreated with melatonin reduced since $6 \mathrm{~h}$ after CHT treatment, and the difference was significant between MT pretreatment and the control all the time except for $36 \mathrm{~h}$ and $4 \mathrm{~d}$. The level of $\mathrm{H}_{2} \mathrm{O}_{2}$ in tomato leaves pretreated with exogenous melatonin was induced between 0 and $12 \mathrm{~h}$ after CHT application, and the content of $\mathrm{H}_{2} \mathrm{O}_{2}$ was significantly different from that of the control all the time except for $3 \mathrm{~h}$. However, the content of $\mathrm{H}_{2} \mathrm{O}_{2}$ in tomato leaves pretreated with exogenous MT was significantly lower than that of the control since $24 \mathrm{~h}$ after CHT treatment. Therefore, it could be observed that MT pretreatment could induce short burst of ROS in plant, and increased the $\mathrm{O}_{2}^{-}$production rate and $\mathrm{H}_{2} \mathrm{O}_{2}$ level in tomato leaves, while decreased significantly since $12 \mathrm{~h}$ after $\mathrm{CHT}$ application, when reactive oxygen species were eliminated gradually to prevent damage from fungicide stress.

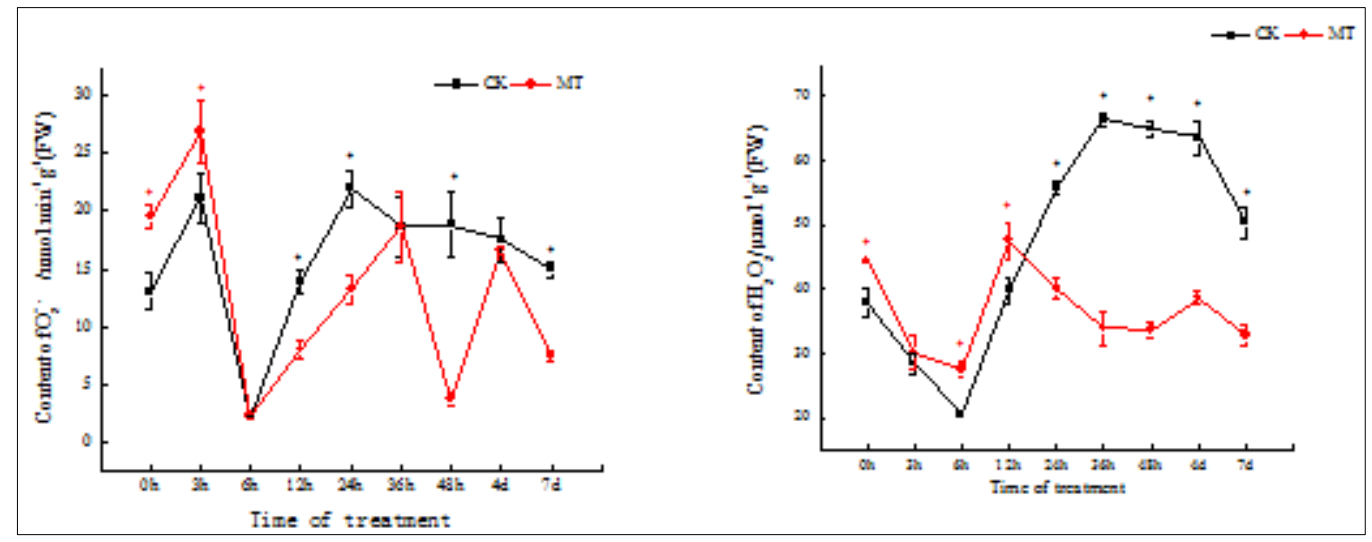

Figure 2. Effects of MT pretreatment on ROS production rate (a) and $\mathrm{H}_{2} \mathrm{O}_{2}$ level(b) in tomato leaves with CHT application

\subsection{Effects of melatonin pretreatment on the rate of GSH/GSSG in tomato leaves with CHT application}

In order to investigate whether glutathione is involved in the regulation of MT pretreatment in the degradation of CHT residue in tomato, GSH/GSSG ratio of CHT exposed plants were detected with MT pretreatment. As shown in Figure 3, compared with the control, MT pretreatment could significantly improve the GSH/GSSG ratio. GSH/GSSG ratio of tomato leaves was significantly higher than that of the control, and the distinct was significant all the time except for $4 \mathrm{~d}$ after CHT exposure. In addition, the GSH/GSSG ratio of CHT exposed tomato plants pretreated with exogenous MT reached its highest peak (13.3) at $3 \mathrm{~h}$ after CHT treatment, which was as twice as that of the control. However, the GSH/GSSG ratio decreased slowly and stabilized at the subsequent time point. Thus, it could be inferred that exogenous melatonin could promote the degradation and metabolism of $\mathrm{CHT}$ residue in tomato plants by regulating the increase of GSH/GSSG ratio. 


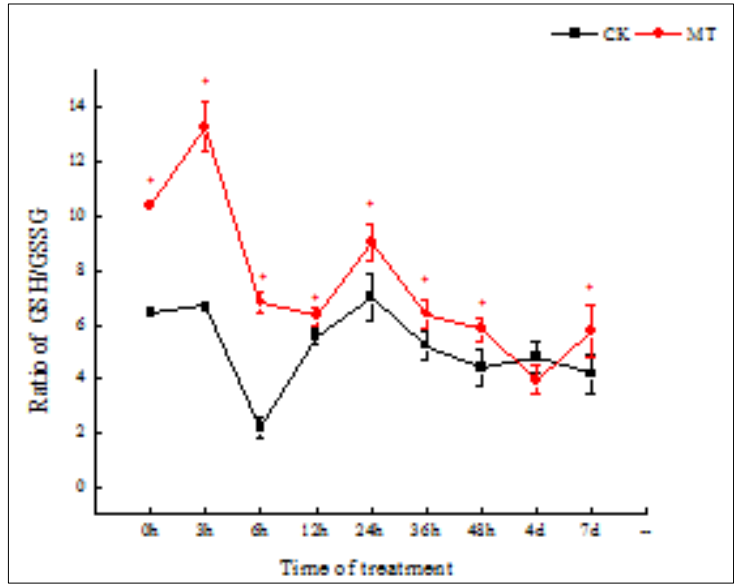

Figure 3. Effects of MT pretreatment on GSH/GSSG ratio in tomato leaves with $\mathrm{CHT}$ application

\subsection{Effects of melatonin pretreatment on antioxidant enzymes activity in tomato leaves with CHT application}

In order to reveal whether exogenous melatonin plays an important role through antioxidant system in regulating the degradation of fungicide residue in tomato, effects of melatonin pretreatment on antioxidant enzymes activity of tomato plants were analyzed (Figure 4). Although it was shown that various changes coupled with the extension of exposure time of CHT due to different antioxidant enzymes, MT pretreatment increased the activity of antioxidant enzymes in CHT exposed plants to different extent. It could be concluded that MT pretreatment increased the activity of SOD in CHT exposed tomatoes all the time, and there was a significant difference between 6 and $36 \mathrm{~h}$ after CHT treatment (Figure 4a). During the period (6-36 h), the activity of POD enzyme of tomato exposed to CHT was also significantly enhanced by pretreatment with MT, while inhibited in the other time (Figure $4 \mathrm{~b}$ ). Exogenous MT pretreatment also significantly promoted the activity of both APX and MDAR enzyme in CHT exposed plants in the period of 0-3 $\mathrm{h}$ and the activity of APX enzyme in the period of 12-48 h, while the activity of MDAR enzyme at the time of 6-24 h was significantly lower than that of the control, with no significant difference at the later stage (Figures $4 \mathrm{c}$ and $4 \mathrm{~d}$ ). It is interesting that the SOD, APX, POD, and MDAR enzymes in tomatoes with MT pretreatment all suggested to be increased first and then decreased, and the peaks of different enzymes appeared in a certain extent. Therefore, MT pretreatment could remove reactive oxygen species by regulating antioxidant enzymes and participate in the regulation of CHT degradation.

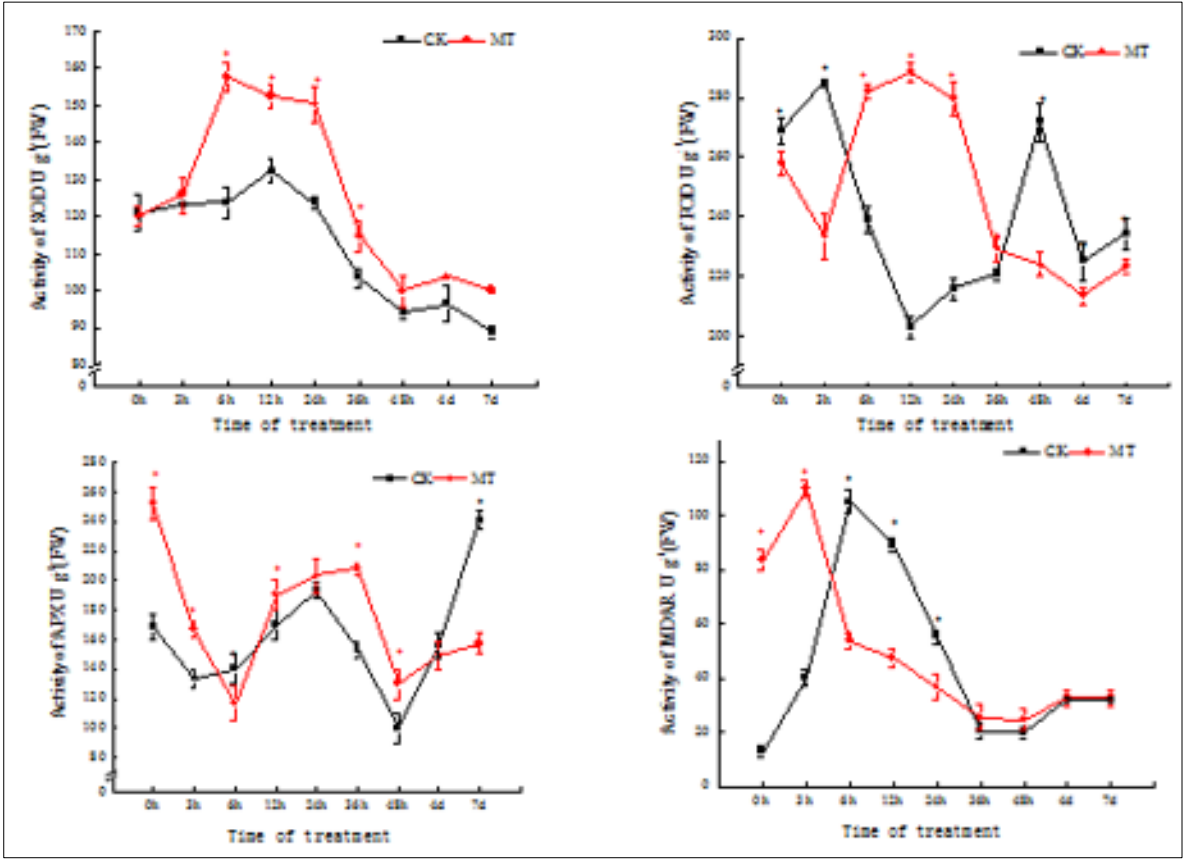

Figure 4. Effects of MT pretreatment on antioxidant enzymes activities of CHT exposed tomato 


\subsection{Effects of melatonin pretreatment on detoxification enzymes activity in tomato leaves with CHT application}

As an important detoxification enzyme, Glutathione-S-transferase (GST) in plant could catalyze the reaction of the exogenous substance or its metabolites with the thiol group of reduced glutathione (GSH) in plant to prevent to be injured. At the same time, reduced glutathione (GSH) was oxidized into oxidized glutathione (GSSG), which could be reduced into GSH by glutathione reductase (GR), resulting in an increase in the content of GSH, as the substrate of GST enzyme, coupled with improvement of the antioxidant capacity of the plant. As shown in Figure 5, melatonin pretreatment increased the GST enzyme activity after exposed to CHT for $24 \mathrm{~h}$. Although the activity of GST enzyme of tomato pretreated with MT was lower than the control during 3-12 h, which was significantly higher than that of the control since $24 \mathrm{~h}$ after CHT exposure. While the activity of GR enzyme in MT pretreated plants was significantly induced during the period of 24-48 h. Thus, exogenous melatonin could play a positive role in the degradation of residue CHT in tomatoes through regulating the activity of GST and GR enzymes.

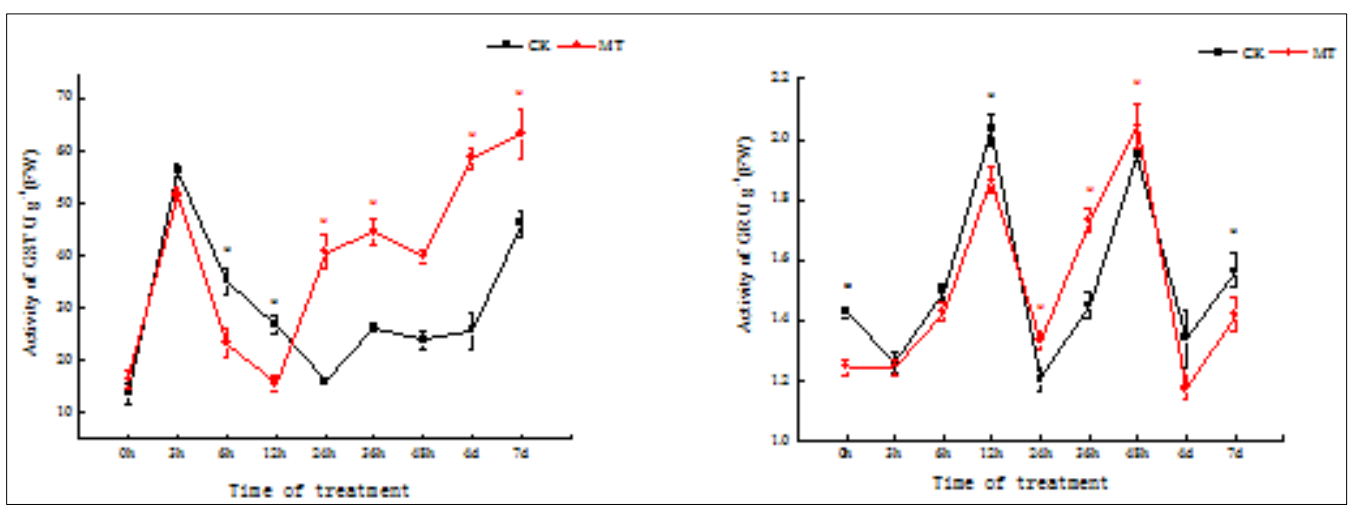

Figure 5. Effects of MT pretreatment on detoxification enzymes activity of CHT exposed tomato

\subsection{Effects of melatonin pretreatment on Non-protein thiol content in tomato leaves with CHT application}

The content of non-protein thiol in tomato could reflect the decomposition products of pesticide to a certain extent, which was associated with glutathione conjugates level. With the extension of CHT exposure time, the level of non-protein thiol in tomato leaves probably indicated an increased trend. Compared with the control, the content of non-protein thiol in tomato was significantly up-regulated with the pretreatment of MT after the application of CHT, particularly from 3 to $36 \mathrm{~h}$ and $4 \mathrm{~d}$ after CHT treatment, the difference between treatments reached the significance level (Figure 6). All the results demonstrated that MT could increase the content of non-protein thiol, and enhanced the metabolism of CHT in tomato plant.

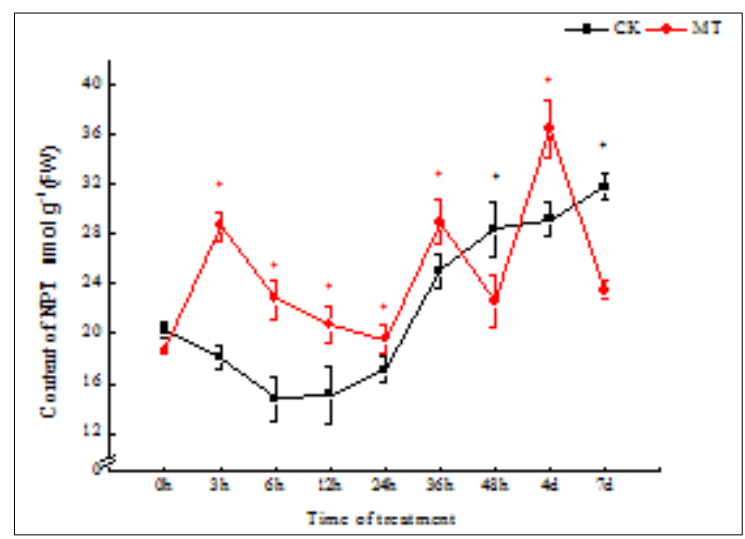

Figure 6. Effects of melatonin pretreatment on content of NPT in CHT exposed tomato 
In fact, it has been explored that plants have developed detoxification mechanism to promote residue herbicide degradation and relieve the negative impacts [8]. However, until now there have been only limited reports on the regulation of degradation of fungicide residues in plant. Hormone has been explored to act as a positive regulation factor to improve plant resistance to abiotic stresses and regulate the mechanism of exogenous substances. It is mentioned that exogenous Brassinosteroids could effectively promote the degradation of pesticides residue in vegetables in our previous study [1]. Here the results also revealed that exogenous MT play an important and positive role in the degradation and metabolism of fungicides residue in plant, as a result of that the residue of chlorothalonil reduced effectively in tomato leaves of pretreatment with MT, a safe, pollution-free and edible substance.

Melatonin has been found to play an important role in plant growth regulation and stress resistance $[17,18]$. It is indicated that MT could not only promote germination of Phacelia tanacetifolia seeds and adventitious root development of tomato $[19,20]$, but also delay drought-induced leaf senescence in apple [21], enhance the resistance of water stress and promote lateral root formation in cucumber [22], alleviate cold stress in Arabidopsis [23], and protect red cabbage seedlings against toxic copper ion [24]. The result also demonstrated that exogenous MT could also alleviate fungicide stress and promote CHT detoxification and degradation in tomato leaves significantly. In addition, it could be observed that MT pretreatment induced short burst of ROS in plant with exposure to CHT, however, decreased the $\mathrm{O}_{2}$ production rate and $\mathrm{H}_{2} \mathrm{O}_{2}$ level significantly in tomato leaves since $12 \mathrm{~h}$ exposed to CHT, resulted in the elimination of ROS to be less injured. It is well known that Melatonin (n-acetyl-5-methoxytryptamine) is small molecular substance with effective antioxidant, which could remove reactive oxygen species effectively, including hydrogen peroxide, peroxide anion, hydroxyl radical, single oxygen and other superoxide radicals $[25,26]$.

Additionally, it is mentioned that melatonin could accelerate the metabolism of superoxide free radicals by improving the activity of antioxidant enzymes in plants, to maintain the dynamic balance between the generation and disappearance of free radicals in plants and alleviate oxidative damage caused by abiotic stress [27]. In fact, MT pretreatment could remove reactive oxygen species by regulating antioxidant enzymes to participate in the regulation of CHT degradation. The result suggested that the activity of SOD, APX, POD and MDAR enzymes were effectively enhanced by MT pretreatment in tomato leaves with application with CHT in a certain extent. It is also reported that MT could increase the activity of antioxidant enzymes in cucumber exposed to salt stress, and promote seed germination under high salinity by regulating antioxidant systems to reduce the level of ROS and $\mathrm{H}_{2} \mathrm{O}_{2}$ in cucumber [28].

The content of NPT, associated with glutathione conjugates level, was significantly increased in MT pretreated plants. However, a pronounced decrease in the residue of CHT was observed. These phenomena provide an important evidence to confirm the participation of glutathione in CHT metabolism in tomato, and CHT is detoxified partly by the formation of glutathione conjugation. It has been mentioned that glutathione could react with a range of substrates including halides and other electrophilic compounds in the presence of the enzyme GST [7]. As a result, the reaction gives rise to the formation of soluble conjugates of pesticide molecule or its metabolites with natural plant constituents, which can be stored in vacuoles during Phase II reactions or conjugated to form nonextractable or bound residue in Phase III reaction to decrease water solubility of pesticide, thereby reduce their reactivity and toxicity [8].

Additionally, it is interesting that glutathione plays a double role in the CHT residue degradation in plant. It is well known that glutathione plays an important role in the regulation of redox homeostasis and redox sensing, although the mechanism in plant is not very clear [29]. It could be inferred that exogenous melatonin could promote the degradation and metabolism of CHT residue in tomato plants by regulating the increase of GSH/GSSG ratio and enhancing the activity of GST and GR enzymes since $12 \mathrm{~h}$ exposed to CHT. Moreover, GSH can be used as the substrate for GST-catalyzed reactions. As a result, the activity of GST enzyme may be influenced by GSH level and the rate of GSSG. While oxidized glutathione (GSSG) can be restored to reduced glutathione GSH (GSH), which also reacts to 
the ratio of GSH/GSSG. It is also possible that the activity of GST and GR are modified by the redox status since they are also subjected to redox regulation [30]. However, glutathione status is involved in $\mathrm{H}_{2} \mathrm{O}_{2}$-triggered signal transduction, which would influence $\mathrm{H}_{2} \mathrm{O}_{2}$ concentration through its antioxidative function [31]. Accordingly, it is still ambiguous whether changes in glutathione status are themselves sensed or rather affect antioxidant enzymes through secondary effects on ROS availability [32-36].

\section{Conclusions}

In summary, the present data demonstrated that exogenous melatonin pretreatment could promote the degradation and metabolism of $\mathrm{CHT}$ residue in tomato plants by inducing the redox signal, improving the antioxidant system, enhancing antioxidant enzymes and increasing the ratio of GSH/GSSG to scavenge reactive oxygen species. And the activity of GST and GR enzymes were also enhanced to conduct detoxification, which result in a pronounced decrease in the residue of CHT in tomato.

Acknowledgments: This work was financially supported by the Natural Science Foundation of Heilongjiang Province (QC2018023), the Postdoctoral Science Foundation of China(2015M581420), the Postdoctoral Science Foundation of Heilongjiang Province (LBH-Z14041), the Fund Program for Overseas Returnees and the National Natural Science Foundation of China (31301769)

\section{References}

1. ZHOU, Y. H., XIA, X. J., YU, G.B., WANG, J. T., WU, J. X., WANG, M. M., YANG, Y. X., SHI, K., YU, Y. L., CHEN, Z. X., GAN, J., YU, J. Q., Brassinosteroids play a critical role in the regulation of pesticide metabolism in crop plants. Sci. Rep., 5, 2015, 1-7.

2. ZHANG, F., QIN, ZH. W., ZHOU, X.Y., XIN, M., LI, SH., LUAN, J., Expression and functional analysis of the propamocarb-related gene CsMAPEG in cucumber. BMC. Plant. Biol., 19(371), 2019, 118.

3. YU, G.B., ZHANG, Y, AHAMMED, G.J., XIA, X.J., Mao, W.H., SHI, K., ZHOU, Y.H., YU, J.Q., Glutathione biosynthesis and regeneration play an important role in the metabolism of chlorothalonil in tomato. Chemosphere. 90(10), 2013, 2563-2570.

4. BUCKER-NETO, L., SOBRAL, PA., MACHADO RD., ARENHART R.A., MARGIS- PINHEIRO, M., Interactions between plant hormones heavy metals responses. Gene. Mol. Biol., 40, 2017, 373-386. 5. ZHANG, F., XIN, M., YU, S.Q., LIU, D., ZHOU, X.Y., QIN, ZH. W., Expression and functional analysis of the propamocarb-related gene CsMCF in cucumber. Front. Plant. Sci., 10, 2019, 871-888.

6. ALAVANJA, M.C.R., ROSS, M.K., BONNER, M.R., Increased cancer burden among pesticide applicators and others due to pesticide exposure. CA-Cancer J. Clin., 63, 2013, 120-142.

7. ROUHIER, N., LEMAIRE, S.D., JACQUOT, J.P., The role of glutathione in photosynthetic organisms: emerging functions for glutaredoxins and glutathionylation. Annu. Rev. Plant Biol., 59, 2008, 143-166.

8. HUBER, C., BARTHA, B., HARPAINTNER, R., SCHRODER, P., Metabolism of acetaminophen (paracetamol) in plants-two independent pathways result in the formation of a glutathione and a glucose conjugate. Environ. Sci. Pollut. Res., 16, 2009, 206-213.

9. GEU-FLORES, F., MOLDRUP, M.E., BOTTCHER, C., OLSEN, C.E., SCHEEL, D., HALKIER, B.A., Cytosolic $\gamma$-Glutamyl peptidases process glutathione conjugates in the biosynthesis of glucosinolates and camalexin in Arabidopsis. Plant Cell., 23, 2011, 2456-2469.

10. WEI, W., LI, Q.T., CHU, Y.N., REITER, R.J., YY, X.M., ZHU, D.H., ZHANG, W.K., MA, B., LIN, Q., ZHANG, J.S., CHEN, S.Y., Melatonin enhances plant growth and abiotic stress tolerance in soybean plants. J. Exp Bot., 66(3), 695-707.

11. TAN, D.X., HARDELAND, R., MANCHESTER, L.C., KORKMAZ, A., MA, S.R., ROSALESCORRAL, S., REITER, R.J., Functional roles of melatonin in plants, and perspectives in nutritional and agricultural science. J. Exp. Bot., 63(2), 2012, 577-597. 
12. SUN, L.Y., LI, X.N., ZONG, SH., WANG, ZH.W., SUN, X.C., ZUH, SHENG, Q., LIU, F.B., SONG, LIU, F.L., WANG, Y.J., Cold Priming Induced Tolerance to Subsequent Low Temperature Stress is Enhanced by Melatonin Application during Recovery in Wheat, Molecules. 23(5), 2018, 10911101.

13. XIA, X.J., WANG, Y.J., ZHOU, Y.H., TAO, Y., MAO, W.H., SHI, K., ASAMI, T., CHEN, Z.X., YU, J.Q., Reactive Oxygen Species Are Involved in Brassinosteroid-Induced Stress Tolerance in Cucumber. Plant Physiol., 150(2), 2009, 801-814.

14. ERKAN, M., WANG, S.Y. H, M.A., LI, Y.B., Glutathione and glutathione-linked enzymes in normal human aorta, WANG, C.Y., Effect of UV treatment on antioxidant capacity, antioxidant enzyme activity and decay in strawberry fruit. Postharvest Biol. Tec., 48(2), 2008, 163-171.

15. ZHU, H., CAO, ZH. X., ZHANG, L., TRU Sic smooth muscle cells: chemical inducibility and protection against reactive oxygen and nitrogen species-induced injury. Mol. Cell. Biochem., 301, 2007, 47-59.

16. YU, G.B., WEI, J.P., CHEN, X.W., LI, X., LI, X., LIU, X.Y., YE, X.T., ZHANG, N., SUN, W.K., The Effect of Glutathione in the Regulation of the Degradation of Residual Fungicide in Tomato. Int. J. Agril. Biol., 20(8), 2018, 1873-1879.

17. ARNAO, M.B., HERNANDEZ-RUIZ, J., Melatonin: plant growth regulator and/or biostimulator during stress. Trends. Plant. Sci., 19(12), 2014, 789-797.

18. REITER, R.J., Oxidative damage in the central nervous system: protection by melatonin. Prog. Neurobiol., 56(3), 1998, 359-384.

19. TIRYAKI, I., KELES, H., Reversal of the inhibitory effect of light and high temperature on germination of Phacelia tanacetifolia seeds by melatonin. J. Pineal. Res., 52(3), 2012, 332-339.

20. WEN, D., GONG, B., SUN, S.S., LIU, S.Q., WANG, X.F., WEI, M., YANG, F.J., LI, Y., SHI, Q.H., Promoting roles of melatonin in adventitious root development of Solanum lycopersicum L. by regulating auxin and nitric oxide signaling. Front. Plant. Sci., 7, 2016, 925-935.

21. WANG, P., SUN, X., LI, C., WEI, Z.W., LIANG, D., MA, F.W., Long-term exogenous application of melatonin delays drought-induced leaf senescence in apple. J. Pineal. Res., 54(3), 2013, 292-302.

22. ZHANG, N., ZHAO, B., ZHANG, H.J., WEEDA, S., YANG, C., YANG, Z.C., REN, S.X., GUO, Y.D., Melatonin promotes water-stress tolerance, lateral root formation, and seed germination in cucumber (Cucumis sativus L.). J. Pineal. Res., 54(1), 2013, 15-23.

23. BAJWA, V.S., SHUKLA, M.R., SHERIF, S.M., MURCH, S.J., SAXENA, P.K., Role of melatonin in alleviating cold stress in Arabidopsis thaliana. J. Pineal. Res., 56(3), 2014, 238-245.

24. POSMYK, M.M., KURAN, H., KAZIMIERZ, M., JANAS, K.M., Presowing seed treatment with melatonin protects red cabbage seedlings against toxic copper ion concentrations. J. Pineal. Res., 45(1), 2008, 24-31.

25. AlLEGRA, M., REITER, R., TAN, D.X., GENTILE, C., TESORIERE, L., LIVREA, M.A., The chemistry of melatonin's interaction with reactive species. J. Pineal. Res., 34(1), 2003, 1-10.

26. TAN, D.X., MANCHESTER, L.C., HARDELAND, R., LOPEZ-BURILLO, S., MAYO, J.C., SAINZ, R.M. , REITER, R.J., Melatonin: a hormone, a tissue factor, an autocoid, a paracoid and an antioxidant vitamin. J. Pineal. Res., 34(1), 2003, 75-78.

27. ZHANG, N., SUN, Q., ZHANG, H., CAO, Y.Y., WEEDA, S., REN, S.X., GUO, Y.D., Roles of melatonin in abiotic stress resistance in plants. J. Exp. Bot., 66(3), 2015, 647-656.

28. ZHANG, H.J., ZHANG, N., YANG, R.C., WANG, L., SUN, Q.Q., LI, D.B., CAO, Y.Y., WEEDA, S., ZHAO, B. REN, S.X., GUO, Y.D., Melatonin promotes seed germination under high salinity by regulating antioxidant systems, ABA and GA4 interaction in cucumber (Cucumis sativus L). J. Pineal. Res., 57(3), 2014, 269-279.

29. MERYER, A.J., HELL, R., Glutathione homeostasis and redox-regulation by sulfhydryl. Photosynth. Res., 86(3), 2005, 435-457.

30. TRACHOOTHAM, D., LU, W.Q., OGASAWARA, M.A., Redox regulation of cell survival. Antioxid. Redox. Sign., 10(8), 2008, 1343-1374. 
31. MHAMDI, A., HAGER, J., CHAAOUCH, S., QUEVAL, G., HAN, Y., TACONNAT, L., SAINDRENAN, P., GOUIS, H., ISSAKIDIS-BOURGUET, E., RENOU, J.P., NOCTOR, G., Arabidopsis glutathione reductase plays a crucial role in leaf responses to intracellular hydrogen peroxide and in ensuring appropriate gene expression through both salicylic acid and jasmonic acid signaling pathways. Plant. Physiol., 153, 2010, 1144-1160.

32. NWANKWOALA, H. O., OMOFUOPHU, E., Investigation of hydrocarbon contaminant levels and groundwater quality assessment in parts of bonny island, rivers state of Nigeria. Cent. Asian. J. Environ. Sci. Technol. Innov., 1(1), 2020, 61-70.

33. NNAEMEKA, A. N., Environmental pollution and associated health hazards to host communities (Case study: Niger delta region of Nigeria). Cent. Asian. J. Environ. Sci. Technol. Innov., 1(1), 2020, 30-42.

34. EBADI, A. G., HISORIEV, H., The prevalence of heavy metals in Cladophora glomerata L. from Farahabad Region of Caspian Sea-Iran. Toxic. Environ. Chem., 99(5-6), 2017, 883-891.

35. YANG1, M., EFEHI, N., JIN, Y., ZHANG, Q., EBADI, A. G., TOUGHANI, M., Hot Water Extraction of Crude Polysaccharide from Codonopsis pilosula and Determination of the Rheological Properties. Rev. Chim., 71(5), 2020, 441-449.

36. YANG, M., MERCY, A. O., EFEHI, N., VENERA, M., LIU, X., EBADI, A. G., TOUGHANI, M., Evaluation of Physicochemical and DPPH. Cleaning Activity of Ultrasonic Assisted Extraction of Polysaccharide from Leonurus japonicas. Rev. Chim., 71(4), 2020, 601-614.

Manuscript received: 2.06 .2020 